\title{
CULTURA E EDUCAÇÃO MATEMÁTICA COMO DIREITO, POSSIBILIDADE, CRIATIVIDADE E MEIO DE APRENDIZAGEM
}

\section{CULTURE AND MATHEMATICAL EDUCATION AS LAW, POSSIBILITY, CREATIVITY AND MEANS OF LEARNING}

\author{
Jefferson Correia da Conceição \\ Universidade do Estado da Bahia - UNEB - Campus II \\ Jeffersoncorreia2@gmail.com
}

\section{Resumo}

Este artigo apresenta reflexões acerca de possíveis articulações de estudos entre os temas Cultura e a Educação Matemática num contexto escolar eleito para pesquisa. Evidencia um panorama de discussões teóricas a respeito da questão a partir de diversos estudiosos do assunto. Analisa a literatura específica no que diz respeito aos objetivos, importância e atualidades acerca das temáticas. A pesquisa configura-se como bibliográfica e de campo. Os dados foram analisados por meio da leitura de bibliografias específicas, observações e dos depoimentos dos participantes. Os resultados iniciais apresentaram percepções relevantes para adoção dos temas para os estudos escolares, apesar dos depoentes, não terem apresentado ou evidenciado nitidamente interlocuções acerca de ambos os assuntos. Concluiu-se que, mediante os estudos sobre Cultura e Educação Matemática articulados é possível dinamizar, motivar e envolver muito mais os educandos com as ações pedagógicas ofertadas na unidade escolar pesquisada, como ponto de partida e estímulos para os estudantes, sobretudo, no que tange ao conhecimento matemático, com uma tessitura mais dinâmica, ativa e prazerosa, mesmo com a necessidade de ajustes ao longo do processo, que se entende, como natural.

Palavras-chave: Educação Matemática. Cultura. Aprendizagem. Mediação.

\begin{abstract}
This article presents reflections about possible articulations of studies between the themes Culture and Mathematics Education in a school context chosen for research. It highlights an overview of theoretical discussions on the issue from various scholars on the subject. It analyzes the specific literature with regard to the objectives, importance and updates on the themes. The research is configured as bibliographic and field. The data were analyzed by reading specific bibliographies, observations and the testimonies of the participants. The initial results showed relevant perceptions for the adoption of themes for school studies, although the interviewees did not present or clearly showed interlocutions on both subjects. It was concluded that, through articulated studies on Culture and Mathematical Education, it is possible to stimulate, motivate and involve students much more with the pedagogical actions offered in the researched school unit, as a starting point and stimulus for students, especially with regard to mathematical knowledge, with a more dynamic, active and pleasant texture, even with the need for adjustments throughout the process, which is understood as natural.
\end{abstract}

Keywords: Mathematical Education. Culture. Learning. Mediation. 


\section{INTRODUÇÃO}

A cultura ocupa um espaço considerável no cotidiano do homem principalmente na contemporaneidade, uma vez que, se pode ampliar por meio da cultura a elaboração do conhecimento para possibilitar o crescimento progressivo das pessoas em relação às experiências e conhecimentos existentes.

Desde o início da história da humanidade a cultura sempre esteve presente em praticamente todas as formações sociais. O conhecimento sistemático da cultura pode abrir perspectivas para que as pessoas possam ter uma compreensão maior do mundo no qual a dimensão simbólica esteja presente: a cultura pode ensinar que é possível transformar continuamente a existência, que é preciso mudar referências a cada momento e ser flexível. Isto quer dizer que criar e conhecer são indissociáveis e a flexibilidade é condição essencial para aprender.

Utilizar a cultura como forma de linguagem e comunicação pode ser também um instrumento eficaz no processo de produção e ampliação de conhecimento dos educandos. Com isso, o conhecimento matemático mediado através da cultura, poderá visar à criação de significações mais expressivas, exercitando fundamentalmente a constante possibilidade de transformação dos educandos, sobretudo no que tange a aprendizagem matemática.

Dessa forma, convêm assinalar que o acesso à cultura poderá possibilitar a apropriação de novas formas de aprendizagem, através das quais se podem expressar os próprios conteúdos dos distintos saberes e aqui se ressalta inclusive os saberes mediados pela escola e que estão presentes no contexto social como um todo.

Com isso, poderiam ocorrer discussões na escola a respeito dos diferentes projetos voltados às áreas de arte e cultura do município, inicialmente, para motivar e tornar mais próximo o conteúdo cultural no que diz respeito aos investimentos financeiros diretos em obras culturais efetivadas ou planejadas por meio dos patrocínios e programas de isenção fiscal para empresas que apóiam o setor cultural, dados esses que poderiam ser obtidos especificamente, na Secretaria de Cultura municipal, dentre outros meios.

Vale salientar, algumas manifestações culturais muito divulgadas na região como: festas literárias (FLICA) na cidade de Cachoeira - BA, FLIGÊ na cidade de Mucugê - 
BA e FLIPELÔ em Salvador - BA, entre outros, que são contempladas por incentivos financeiros governamentais, que poderiam ser considerados como motivos ou ponto de partida para pesquisas e, posteriores discussões no que tange ao conhecimento matemático por meio dos investimentos, participações dos visitantes, número de expositores nos eventos ligados à cultura etc. (REVISTA TERRA MÃE, 2018).

Existem programas de incentivos como o FAZCULTURA do Governo Estadual da Bahia e outros do Governo Federal, dentre outras políticas públicas que apóiam o setor cultural e que objetivam o desenvolvimento social, como o Fundo de Cultura que garante uma parcela da arrecadação do ICMS - Imposto sobre Circulação de Mercadorias e Serviços, do Estado da Bahia para ser investido na área cultural.

O Fundo de Cultura é o principal mecanismo de fomento da SECULT - Secretaria de Cultura do Estado da Bahia para serem investidos na área cultural, que é estruturado em linhas de apoio para ações culturais continuadas, eventos culturais calendarizados, mobilidades artísticas e culturais, editais setoriais etc. (REVISTA TERRA MÃE, 2018).

Além disso, as festas regionais como o Carnaval, os ciclos juninos, festas dos padroeiros, entre outras, poderiam também se constituir num importante ponto de partida para discussão dos aspectos culturais, matemáticos e estatísticos, vislumbrados conjuntamente - docentes e educandos para discussão de questões matemáticas, podendo gerar problemas com distintas operações, pois se podem considerar todos ou alguns investimentos recebidos e os resultados financeiros gerados pelos eventos.

O quantitativo de trabalhadores envolvidos - geração de trabalhos e de rendas em distintas escalas, assim como os serviços prestados, os setores envolvidos e beneficiados - hotéis, comércio, indústrias, setor turístico, preparação fantasias, restaurantes, numa percepção macro dos eventos culturais articulados com o conhecimento matemático poderia se constituir também numa fonte de assuntos e conteúdos para motivar aprendizagem matemática e estatística.

São questões apenas sugeridas e pontuadas, que poderiam ser trabalhadas de forma sistemática, num ritmo próprio e estabelecidas pelos envolvidos para serem pesquisadas, pensadas e dialogadas, a bem de algumas articulações entre a cultura e o conhecimento matemático nos distintos ciclos da educação básica, ou quem sabe, até mesmo no ensino superior, favorecendo na criação de operações e problemas 
matemáticos apoiados nos citados conceitos e questões culturais.

Pesquisas com base nesse viés de informações poderiam ser largamente viabilizadas, podendo favorecer a articulação de conhecimentos matemáticos tão necessários para escola e para sociedade em geral.

A opção por valorizar e buscar tais saberes, poderia criar ações que primassem pela cooperação, por usar e perceber o espaço cultural local, inicialmente, como fonte de estudos de diferentes formas, pelos diálogos com os diversos atores culturais que poderiam proferir mediante um trabalho coletivo, objetivando-se permitir um importante passo para a superação de dicotomias teorias-práticas no que tange às estruturas das componentes curriculares e áreas de conhecimentos, como se não fosse possível enxergar caminhos comuns entre o que se apresenta, aparentemente, como totalmente diferentes.

Com isso, este estudo tem como propósito abordar a compreensão dos estudantes do $3^{\circ}$ ano do ensino médio do Centro Territorial de Educação Profisssional do Litoral Norte e Agreste Baiano - CETEP-LN, na cidade de Alagoinhas - BA, sobre a cultura e suas modalidades e possíveis articulações com a aprendizagem matemática, ao se tentar estabelecer ou procurar algumas conexões com o conhecimento matemático mediado pela escola até o momento da realização da pesquisa, sob o olhar dos educandos num viés quer transdisciplinar e/ou interdisciplinar.

Como problema para a pesquisa destacou-se: em que medida a cultura pode ser um elo facilitador para aprendizagem matemática? Tal problema tem como propósito verificar como o conhecimento matemático pode ser assimilado mediante a cultura em geral, sem desconsiderar as manifestações culturais do âmbito da cidade de Alagoinhas BA, lócus dos estudantes participantes.

Pesquisas foram realizadas sobre o assunto, mas, acredita-se na possibilidade de novas verificações, indagando-se o grau de interferência dos fatores culturais e suas relações com a aprendizagem matemática.

Com esse propósito, se podem mencionar algumas pesquisas antecedentes com as duas abordagens - Cultura e Educação Matemática, que foram realizadas por: Maria Aparecida Viggani Bicudo (2005) por conceituar e abordar aspectos relevantes, atuais e necessários a respeito da Educação Matemática; Ubiratan D’Ambrosio (1986) em razão das inúmeras pesquisas, trabalhos, palestras e colocações significativas no que tange a 
Educação Matemática e suas tessituras com assuntos, temas e práticas sócios- escolares.

Indiscutível também, o aporte de Paulo Freire (1996) em face de todas as abordagens referentes à educação num viés para além da aprendizagem escolar e Iran Abreu Mendes (2017) pelo conhecimento oriundo de inúmeras pesquisas que consideram as práticas culturais de diversos povos em vários continentes e suas interlocuções com o conhecimento matemático, entre outros estudiosos do assunto.

\section{METODOLOGIA, PÚBLICO ALVO E LOCAL DA PESQUISA}

Os participantes da pesquisa foram eleitos em face da necessidade de se estudar parte de um universo local, visto que a pesquisa tem por propósito generalizar os resultados individuais coletados, para considerar a população da qual os sujeitos pesquisados constituem uma amostra.

Por tais motivos, optou-se pela pesquisa randômica (SOARES, 1991) que orienta uma distribuição aleatória intencional dos instrumentos, contudo, com moderado controle em face dos objetivos do trabalho, sem comprometer a intencionalidade quantitativa e qualitativa da coleta de dados, com o apoio de questionários, para permitir a cada um dos educandos participantes iguais chances de serem selecionados, para compor um grupo de 45 (quarenta e cinco) estudantes do $3^{\circ}$ ano do Ensino Médio, correspondendo a 31,5\% de um total de 123 (cento e vinte três) discentes da série mencionada no turno vespertino.

Foram pesquisadas quatro turmas do $3^{\circ}$ ano do Ensino Médio, tendo em cada uma delas em torno de 30 (trinta) educandos, sendo 77 (setenta e sete) do sexo feminino e 46 (quarenta e seis) do sexo masculino. A faixa etária dos participantes da pesquisa dos 17 aos 21 anos, oriundos das áreas urbana e rural do município.

Os questionários foram aplicados durante um período de 03 (três) semanas, em dias alternados e distintos, utilizando-se no total quatro turnos em horários variados e disponibilizados pela gestão escolar, previamente agendado com as séries, no turno vespertino, para não comprometer o andamento das atividades docentes na unidade escolar.

Vale ressaltar, que em um dos turnos utilizados para pesquisa, foi possível ter acesso a uma sala de aula num horário vago, em virtude da ausência de um dos docentes por motivos de saúde. Nos demais momentos, foi possível contar, voluntariamente, com a 
colaboração dos docentes que se encontravam nas salas de aula.

Cada questionário precisou em média de 35 minutos para preenchimento, por parte dos estudantes, contemplando questões tais como: que é cultura? As manifestações culturais são importantes para as pessoas? Comente. Quais as manifestações culturais que você conhece? Você vê alguma relação entre a Cultura e a Matemática? Comente. Que é Matemática? Dentre outros.

O propósito foi efetivar pesquisa qualitativa, para percebermos se havia alguma percepção dos educandos depoentes no que diz respeito a possíveis articulações entre a Cultura e a Matemática, querendo com isso, perceber-se a realidade social que é mais rica que qualquer teoria, qualquer pensamento e qualquer discurso que se possa elaborar sobre ela, mas principalmente, o entendimento dos educandos sobre o assunto.

A delimitação do ambiente aconteceu em razão do Centro Territorial ser o espaço natural de encontro dos participantes da pesquisa e, por isso, o CETEP-LN, foi escolhido por ser representativo na cidade, ser uma escola pública estadual de tradição no município, pelos serviços prestados à comunidade ao longo de anos e pelos efeitos e impactos positivos na comunidade, que podem ser verificados mediante os distintos profissionais oriundos da unidade escolar, ou seja, ex-estudantes, que atuam não somente na cidade de Alagoinhas - BA, mas também no entorno social.

\section{NO QUE DIZ RESPEITO À EDUCAÇÃO MATEMÁTICA}

A Educação Matemática foi concebida mediante ações reflexivas, almejando-se um ensino que possibilitasse aos estudantes proceder a análises, discussões, conjecturas, apropriação de conceitos, formulação de idéias, ou seja, de amplitudes conceituais significativas a respeito de distintos assuntos, sempre articulados com o conhecimento matemático, propriamente dito.

Acredita-se que assim, algumas abordagens sobre a Cultura que seja apoiada em metodologias adequadas e dialogadas com áreas de conhecimentos, neste caso a Educação Matemática, poderiam conferir ao currículo e, por conseguinte as ações pedagógicas por esse viés, uma perspectiva de totalidade, respeitando-se evidentemente, as especificidades epistemológicas das respectivas áreas de conhecimentos.

Desse modo, podem-se destacar as características da Educação Matemática para 
fundamentar, realçar e incentivar a compreensão matemática como um todo, uma vez que, tais conhecimentos poderão ser assimilados e produzidos em qualquer espaço e por muitas pessoas, desde que mediados de maneira conveniente e planejados. Neste sentido, Silva (2006, p. 43) diz que "Em especial, a Matemática, como linguagem, tem o caráter de universalidade, assim como a música, a arte e outras manifestações culturais. Essa universalidade da linguagem matemática mostra a sua utilidade na comunicação".

Por assim entender, a Matemática se torna uma ligação entre campo de conhecimento e disciplina escolar (HELBEL, 2013), justamente por possuir este caráter articulador com outras áreas de conhecimento. Para Cifuentes (2005, p. 59) a compreensão é a seguinte:

A Matemática não deveria ser estudada priorizando-se apenas seus conteúdos, senão interpretada também em seus contextos históricos e culturais, e pondo em evidência não somente sua utilidade senão também a sua beleza, imbricada com outras áreas de conhecimentos ou campos de atuação.

Perante a Diretriz Curricular de Matemática, da Secretaria de Estado da Educação - BA (SEED, 2008) para a Educação Básica da Rede Pública, os conteúdos de grande amplitude, são entendidos como Conteúdos Estruturantes, organizando-se em: números e álgebra, grandezas e medidas, geometrias, funções e tratamento da informação.

Portanto, mediante os conteúdos estruturantes mencionados e por intermédio de um projeto com características integracionistas, pode-se explicitar a articulação da Cultura e suas modalidades com o conhecimento matemático, com reflexões, ponderações e transformações, podendo ser uma produção conjunta entre a percepção cultural, a consciência individual e coletiva, articulados intencionalmente mediante projetos pedagógicos, que considerem os conteúdos matemáticos estruturantes, associados com aspectos culturais, na medida possível, de maneira planejada, dialogada e intencional, como ponto de partida para ações pretendidas.

Nesse viés, salientam-se os PCN de Matemática (1998, p. 28) quando explicitam que:

[...] é importante que a Matemática desempenhe, [...] equilibrada e indissociavelmente, seu papel na formação de capacidades intelectuais, na estruturação do pensamento, na agilização do raciocínio do aluno, na sua aplicação a problemas, situações da vida cotidiana e atividades do mundo do trabalho e no apoio à construção de conhecimentos em outras áreas curriculares. 
Dessa maneira, pode-se perceber a importância da utilização do conteúdo cultural como ponto de estímulo e conhecimento enquanto tema transversal para o desenvolvimento de alguns conhecimentos matemáticos, pois além de proporcionar momentos de entretenimento e socialização poderá favorecer na elaboração de informações.

Assim, a Educação Matemática envolve além da Matemática propriamente dita, outras áreas de conhecimentos como: Sociologia, Política, História, Artes e inúmeras outras estimulando inclusive a multidisciplinaridade. Para D’Ambrósio (1986, p.35) a percepção sobre tal questão é a seguinte:

Sem dúvida, Educação Matemática poderia ser caracterizada como uma atividade multidisciplinar, que se pratica com o objetivo geral bem específico transmitir conhecimentos e habilidades matemáticas - através dos sistemas educativos (formal, não formal e informal).

Como se percebe, a Educação Matemática poderá estar relacionada intrinsecamente com a Cultura e, paulatinamente, mediante conceitos, definições matemáticas, com a utilização de regras, instruções, operações, deduções e algumas operações e estas, são características essenciais para o trabalho pedagógico neste campo de conhecimentos.

Ainda segundo os PCN de Matemática (1998, p. 24) “[...] A Matemática caracteriza-se como uma forma de compreender e atuar no mundo e o conhecimento gerado nessa área do saber como um fruto da construção humana na sua interação constante com o contexto natural, social e cultural".

De fato, deve-se levar em consideração que muitas vezes os conhecimentos matemáticos são desenvolvidos conforme eram concebidos nos seus primórdios, como sendo uma ciência que apenas poderia solucionar problemas do cotidiano. O que se tem geralmente é uma socialização de forma engessada, desvinculada do cotidiano do educando e com isso, podem-se prejudicar a obtenção da aprendizagem matemática em muitos aspectos.

De acordo com os Parâmetros Curriculares Nacionais (PCN):

$\mathrm{Na}$ maioria das vezes, subestimam-se os conceitos desenvolvidos no decorrer da atividade prática docente, de suas interações sociais imediatas, e parte-se para o tratamento escolar, de forma esquemática, privando os alunos da riqueza de conteúdo proveniente da experiência pessoal. (BRASIL, 1997, p. 22-23).

Para Oliveira, Carvalho e Figueiredo (2001), a matemática: "possui um caráter 
aversivo construído historicamente, uma vez que, dentro e fora do contexto escolar, aprendem que esta disciplina exige muito esforço ou que é muito difícil” (OLIVEIRA; CARVALHO; FIGUEIREDO, 2001, p. 26, apud MONTEIRO; MEDEIROS, 2002, p. 73).

Oliveira, Carvalho e Figueiredo (2001, p. 17) ainda pontuam que:

A aprendizagem se incrementa por meio da interação do aprendiz com o seu mundo físico e social, pela mediação dos procedimentos de ensino, pelas formas de intervenção no mundo, por meio das diversas linguagens e dos conhecimentos elaborados culturalmente, considerando a sua função coletiva, a sua organização dentro das suas peculiaridades e especificidades em cada momento histórico. A complexidade do processo de aprendizagem se estabelece quando os significados são contextualizados e compreendidos, possibilitando a generalização e a discriminação, nesse processo, a linguagem promove que os códigos elaborados coletivamente e imbricados na situação social representem a dinâmica cultural e individual das pessoas.

Desse modo, a Educação Matemática não deve realizada de forma engessada, limitada somente à mera transmissão de conhecimentos, mas deve oportunizar aos educandos, de maneira autônoma, a buscar caminhos para a construção do conhecimento e, consequentemente, sua formação científica, considerando-se os conhecimentos prévios adquiridos no cotidiano cultural.

É imprescindível que o docente mediador estimule o educando, desafie-o, proporcionando-lhes uma educação matemática dinâmica que ressalte as experiências culturais vivenciadas, que o capacite para uma melhor adaptação e incite-o ao conhecimento, uma vez que, esse sujeito sofre influências do contexto social e cultural que vive.

Desse modo, os PCN de Matemática (1998, p. 111) explicitam que:

Aprender Matemática de uma forma contextualizada, inteirada e relacionada a outros conhecimentos traz em si o desenvolvimento de competências e habilidades que são essencialmente formadoras, à medida que instrumentalizam e estruturam o pensamento do aluno, capacitando-o para compreender e interpretar situações, se aprimorar de linguagens específicas, argumentar, analisar e avaliar, tirar conclusões próprias, tomar decisões, generalizar e para muitas outras ações necessárias à sua formação.

Portanto, a Educação Matemática pode também usufruir como ponto de partida dos jogos, brinquedos infantis, adivinhas, contos, lendas, cantigas, músicas em geral, trava línguas ${ }^{1}$ conduzindo ao aprendizado dos valores matemáticos e à solução de

\footnotetext{
${ }^{1}$ Disposição lingüística, em prosa ou verso, caracterizada, e de tal forma ordenada, que se torna extremamente difícil e, às vezes, quase impossível, pronunciá-la sem tropeços. Podem agrupar múltiplas
} 
problemas.

Algumas lendas e contos podem funcionar como centro de interesse, permitindo sugestões para a idéia de par, conhecimento das horas, dúzia e meia-dúzia ou/e dezena e centena, metro, decímetro, formas geométricas, além de contribuir para melhoria da interpretação e compreensão do mundo cultural, inclusive com questões atuais no que diz respeito à economia podendo facilitar este tipo de comunicação com assimilações conceituais significativas.

Para Oliveira (2014, p.37) a compreensão sobre esta articulação é a seguinte:

A comunicação em Matemática tem um papel importante, pois, ajuda os alunos a estabelecerem vínculos entre a linguagem simbólica e abstrata da matemática. Assim, quando incentivados a se comunicarem matematicamente, com os que o cercam, eles terão a oportunidade de adquirir novos conhecimentos e diferentes opiniões sobre um determinado assunto e assim aprender matemática de maneira significativa, através do confronto de ideias.

Por isso, a cultura e suas manifestações poderão fazer o raciocínio partir de uma simples unidade e atingir uma grandeza imensurável, com o apoio de uma infinidade de publicações, algumas de caráter popular, outras de escritores especializados, que apresentam curiosidades matemáticas baseadas na cultura popular, que poderão atuar como ponto de partida para aprendizagem matemática (BRANDÃO, 2012).

Nesse sentido, vale ressaltar o que coloca Machado (2002, p. 70) sobre essa questão:

[...] os jovens deveriam dispor de um conjunto de aptidões gerais científicas e literárias, de capacidade de julgamento crítico e de um bom domínio básico dos três pilares do saber: as matemáticas, as ciências e a tecnologia; a cultura humanística; e as disciplinas socioeconômicas. Deveriam saber também se comunicar, assumir responsabilidades e integrar-se ao trabalho em equipe.

Pelo exposto, pode-se verificar a importância de projetos e ações pedagógicas articuladores, que considerem a Cultura enquanto tema transversal que poderá facilitar a mediação da Educação Matemática, como ponto de partida e centro de interesses em inúmeros contextos sócios escolares.

\section{NO QUE DIZ RESPEITO À CULTURA}

Atualmente, constata-se a importância de definir cultura como um processo social,

espécies do folclore narrativo, do folclore poético e do folclore lingüístico. Rima criativa, em versos. (FERREIRA, 1999, p.1994) 
como algo que se produz, circula e consome na sociedade, ressaltando-se os estudos sobre recepção e apropriação de bens, significados e mensagens culturais nas sociedades contemporâneas (MACHADO, 2002).

Assim, cabe-nos aqui, apresentar algumas colocações sobre as formas culturais e suas peculiaridades.

\title{
CULTURA POPULAR E CULTURA ERUDITA
}

Para compreender qualquer cultura, deve-se percebê-la como algo singular, com vida própria, dinâmica, plena e representativa; enfim, como algo genuíno e integrado a vida das pessoas. Vejamos alguns argumentos colocados sobre o assunto por Aranha (2014, p.40) diz que:

\begin{abstract}
[...] quando contrapomos, por exemplo, cultura de elite e cultura popular, já estamos emitindo juízos de valor: a cultura de elite seria superior porque refinada, elaborada, ao passo que a cultura popular seria inferior por se tratar de expressão ingênua e não-intelectualizada. Outra confusão está em se identificar cultura de elite (que na verdade é a cultura erudita) com produção da classe dominante. De maneira geral, isso se deve ao pressuposto de que a verdadeira cultura é a produzida pela elite. [...] quando se fala de conhecimento, despreza-se o saber popular para se valorizar apenas a ciência; ao se tratar da técnica, exalta-se a mais refinada tecnologia; ao se referir à arte contemporânea, pensa-se nas pinturas de Picasso; e, quando se volta a atenção para a arte popular, é para considerá-la de forma depreciativa, como arte menor ou produção exótica e objeto de curiosidade.
\end{abstract}

Neste sentido, pode-se afirmar que o fato cultural é imemorial e, como cultura empírica, surgiu quando o homem tentou resolver e compreender as dificuldades e facilidades do seu habitat relacionadas com a sobrevivência, subsistência e perpetuação da espécie. Sabe-se que a cultura se mantém no universo, num processo de adequação, de flexibilidade, quando pressões externas ou internas atuam e impõem modificações.

Dependente de um condicionamento social é objeto de interferência, reconstituição, aniquilamento, às quais responde pacífica ou resistentemente. Da cultura popular saíram às elaborações manifestadas que, em condições outras, atingiram fins outros, construindo o lastro da cultura erudita por perceber-se que esta se apropria de alguns valores da cultura popular para fazer valer os seus intentos (SAVIANI, 2013).

De acordo com M. Ayala (2015, p. 51), a cultura popular tanto veicula os pontos de vista e interesses das classes subalternas, numa perspectiva de crítica à dominação, mais ou menos consciente, quanto internaliza os pontos de vista e interesses das classes 
dominantes, legitimando a desigualdade existente.

Entre a cultura popular e a erudita há modelos intermediários, porosos e mutáveis. Os próprios limites da cultura popular e da erudita não se caracterizam pela impermeabilidade, ao contrário, da fricção contínua entre uma e outra, observam-se os fenômenos da descensão, quando complexos culturais eruditos são absorvidos pelo povo e de ascensão, quando os complexos culturais do meio popular são absorvidos pelos eruditos (M. AYALA, 2015, p. 88).

A cultura popular difere da cultura erudita por ser produzida por aqueles mesmos que a consomem. Constitui-se numa produção elaborada pelo próprio grupo, caracterizando assim o valor de uso da cultura. Estabelecem questionamentos, recusas, contestações às normas e valores estabelecidos. É extremamente útil em seu papel de fixação e auto-reconhecimento do indivíduo dentro do grupo (COELHO, 2014).

Diante disso, pode-se perceber que a cultura erudita, constitui-se de todos os produtos e manifestações canonizadas pela crítica erudita. Valoriza o que está assegurada pela aceitação das classes sociais favorecidas. Ela pode ser entendida como sistema específico que, articulando a outros, forma o que se pode denominar, em consonância com os meios formais, uma cultura apoiada no sistema dominante.

\section{CULTURA E CULTURA DE MASSA}

Os seres humanos devem seu predomínio atual, em parte a sua capacidade mental, mas ainda mais às suas idéias, hábitos e técnicas que foram transmitidos pelos ancestrais. Tendo nascido numa sociedade qualquer, o ser humano descobre que a maioria dos problemas que se apresentam durante sua vida já foram enfrentados e resolvidos pelos que the antecederam. Cabe-lhe apenas aprender as soluções. Se conseguir fazer este aprendizado com êxito, não terá necessidade de muita especulação.

Por esse caminho, percebe-se que a cultura de massa está fortemente vinculada ao fenômeno do consumo, sendo que o momento de propagação dessa cultura ocorre por interferência decisiva dos meios de comunicação.

Constitui-se numa cultura elaborada para amplo público, destilando esquemas simplificadores e caracterizada pelo fato de não ser feita por aqueles que o consomem. É fortemente influenciada e alimentada por uma economia baseada no consumo de bens, 
numa economia de mercado (COELHO, 2014).

É uma cultura impulsionada pela sociedade de consumo que aliena e reduz a capacidade de autocrítica, assim como da sociedade como um todo. No entanto, também é dotada de força e motivação em sua banalidade, responsável por um dinamismo capaz de fazê-la romper barreiras de classes sociais e culturais, colocando em comum algumas manifestações que outrora eram características de outras camadas sociais (COELHO, 2014).

Poderá também, beneficiar o desenvolvimento do homem, em virtude da sua própria dinâmica interior, permitindo um domínio mais rápido das concepções de mundo, uma vez que, o acúmulo de informação poderá transformar-se em formação, pois, a quantidade poderá provocar alterações na qualidade (COELHO, 2014).

Assim, pode-se perceber que o rumo e a velocidade das transformações do mundo moderno exigem cada vez mais, de todos os homens, uma constante verificação dos conhecimentos adquiridos e uma contínua readaptação a um mundo que, afinal, é dinâmico e mutável, sendo, portanto, parte do contexto educacional.

Por fim, as práticas socioculturais podem ser compreendidas como os saberes e fazeres de grupos sociais no interior de uma cultura específica. São desenvolvidas na busca de soluções para problemas singulares que surgem na vida das diversas comunidades humanas. Elas contribuem para vencer os desafios cotidianamente enfrentados pelas sociedades, na superação de suas dificuldades e conforme as necessidades de cada grupo.

Tais práticas socioculturais, conforme os propósitos podem ser inovadoras, restritivas, direcionadas ou tradicionais, conforme os interesses individuais ou coletivos, e de acordo com as características culturais do lugar onde são desenvolvidas.

\section{RESULTADOS E DISCUSSÕES}

Não ficou evidente inicialmente, através das informações colhidas dos educandos participantes da pesquisa, que a cultura enquanto abordagem prática e conceitual poderia ser um canal importante como ponto de partida para aprendizagem matemática, pois $(93,4 \%)$ dos respondentes, cerca de 42 (quarenta e dois) depoentes dos 45 (quarenta e 
cinco) que participaram dos estudos, não afirmaram enfaticamente e com segurança evidências de tais possibilidades articulativas.

Foram coletados no início dos trabalhos depoimentos vagos, soltos e tímidos sem estabelecer conexões claras entre as áreas de conhecimentos, sem evidências e comentários que ressaltassem ligações das possibilidades de comunicação entre matemática e cultura de forma clara e segura. Assim, vejamos abaixo algumas colocações ao responderem sobre Cultura e Matemática interligadas:

Estudante 22 - Pra mim cultura é tudo. Carnaval, futebol, samba, capoeira e outras coisas. Agora junto com matemática nem sei como. Acho que pode...

Estudante 15 - Quando estudei sobre folclore lá no primário a professora [...] falava alguma coisa sobre cultura. Então pra mim é isso. Matemática é outra coisa...

Estudante 27 - Meu baba é minha cultura, pois todos nós lá onde moramos gostamos muito. Depois disso, vem a micareta, o São João e tudo mais. Matemática não tem nada a ver estudar junto...

Estudante 13 - Como assim? O que tem a ver? Cultura e Matemática? Só se for na hora de contar o dinheiro de pois da festa, da feira. Só se for assim ... não sei o que tem a ver cultura e matemática.

Contudo, em relação à opinião sobre o que é cultura, verificou-se que (100\%) dos entrevistados disseram de maneira geral que a cultura é importante, pois na opinião deles existem ligações entre as áreas de conhecimentos culturais e na maneira de serem realizadas, apresentadas e perpetuadas, sem falar nos motivos em comum que lhes dão origem, ou seja, a criatividade, a história, a emoção e a intenção das pessoas, o bem querer dos encontros populares, mesmo não a articulando com o conhecimento matemático.

Percebeu-se também, que $(32 \%)$ dos entrevistados entendem o que é cultura popular, mas que não a vivenciam numa intensidade que poderiam, em virtude dos apelos da cultura de massa que pode comprometer assim, em parte, a visibilidade de outras manifestações culturais, percebendo-as timidamente, como veículo que poderia estar facilitando a aprendizagem, inclusive com entrosamento com a matemática na instituição escolar.

Dessa maneira, apesar dos depoentes terem respondido de maneira expressiva $100 \%$, de forma correta e coerente quando se perguntou o que era cultura; se as manifestações culturais são importantes para as pessoas e quais as manifestações culturais que conheciam, constatou-se que o mesmo não ocorreu $(93,4 \%)$ quando os 
questionamentos realizados foram: se notavam alguma relação entre a Cultura e a Matemática e o que entendiam como Matemática, pois foram coletadas respostas soltas e sem sentido, mostrando-se a falta de entendimento da maioria dos educandos depoentes sobre o assunto de maneira articulada.

Interessante ressaltar também, enquanto aspectos positivos do trabalho de pesquisa as variadas falas dos depoentes acerca das suas experiências na escola diante do fato cultural, no que tange às lembranças e alegrias (46\%), bem como, do que gostaram ou não.

Por outro lado, alguns estudantes se detiveram mais com suas respectivas predileções nas atualidades culturais de massa $(85 \%)$ e outros falaram mais sobre o passado cultural (67\%). Mas constatou-se que, os participantes se sentiram valorizados e importantes, sendo que nenhum deles desconsiderou a cultura enquanto manifestação significativa para vida das pessoas.

Dentre os participantes era transparente o respeito e o interesse pelas tão diferentes falas que emanavam dos seus pares, com seus significados e lembranças a respeito da cultura, mesmo com vagas imbricações com o conhecimento matemático.

Assim, pode-se verificar que mesmo de maneira fragmentada sem articular as duas áreas de conhecimentos, que havia motivações, envolvimentos e participação até mesmo dos estudantes mais tímidos, num ambiente rico e muito dinâmico, que nos impulsionou a elaborar um todo coeso a partir dos depoimentos coletados, ainda que, não estivessem articulando os conhecimentos - cultura e matemática com clareza.

Mesmo assim, o trabalho avançou de acordo com o envolvimento e boa vontade dos participantes que, a partir da reflexão, do estudo, das análises, dos comentários que surgiam, iam colocando novas questões, novos desafios, que foram aproveitados para elaboração das análises, ao aguçarem curiosidades, buscarem conhecimentos, fontes, reminiscências diversas, histórias, novos questionamentos que nos colocou em contato com diferentes experiências de vida, uma verdadeira rede de saberes que estavam contidos, limitados e escondidos.

De fato, esta riqueza nos despertou ainda mais o interesse pela pesquisa, ao proporcionar a produção de um texto motivador de aprendizagens e, como não poderia deixar de ser, com participações ativas diante dos objetivos propostos inicialmente para o 
trabalho, pois as questões tratadas pelas narrativas e depoimentos escritos trouxeram subsídios para as discussões em sala de aula, apesar de não terem destacado com clareza as ligações entre a cultura e o conhecimento matemático.

Desse modo, entendeu-se que existe a necessidade de diálogos pedagógicos a respeito das temáticas na unidade escolar abordada, que poderão ocorrer por meio das reuniões para as atividades complementares (AC); semanas pedagógicas e projetos, rodas de conversas, oficinas pedagógicas temáticas, entre outras ações comuns, preferencialmente, com a participação da comunidade escolar envolvida - docentes, coordenadores, gestores e discentes.

Esclarece-se que os aspectos que caracterizam os trabalhos analisados poderão ser utilizados como parte das atividades pedagógicas e planejamentos escolares, pois poderão servir como apoio e referência para o que vier a ser realizado pelos participantes docentes e discentes, principalmente, por refletir opiniões acerca do assunto na unidade escolar pesquisada.

Acredita-se que assim, os participantes poderão perceber melhor as informações que lhes são apresentadas cotidianamente no contexto escolar ao poderem contribuir para ampliar as respectivas possibilidades de participação social, no que tange ao conhecimento da cultura e da matemática de modo mais amplo e articulado, sobretudo, diante dos resultados, como os constatados pela pesquisa e que poderão favorecer a retroalimentação das ações por este viés proposto - cultura e conhecimento matemático associados.

Com base no trabalho de pesquisa efetivado foi possível constatar comportamentos positivos (100\%) manifestados pelos depoentes, tais como: a participação ativa, a socialização de experiências, o envolvimento, a disposição dos participantes para aprender, realizar, desenvolver e comunicar suas opiniões e algumas articulações conceituais ressaltadas pelos participantes no andamento dos trabalhos, sendo importante também, entre outras coisas, para a discussão da cultura e do conhecimento matemático numa perspectiva de alimentar o debate e o diálogo no contexto escolar, entre outros aspectos.

Convém aqui, ressaltar a permanente necessidade de aumentar as discussões em torno da questão central do projeto que é a articulação entre os assuntos citados, partindo- 
se da premissa de mobilidade e dinamismo da escola formal e da efetivação de práticas pedagógicas que visem o aprimoramento permanente do trabalho docente adequado à realidade, onde se entende que aprender Matemática por meio da Cultura pode ser uma possibilidade a ser vislumbrada em sala de aula, já que se sobressaiu o fato de $(100 \%)$ dos participantes acreditarem que tanto a Cultura quanto a Matemática são áreas importantes, mesmo sem perceberem-nas inicialmente de maneira articulada.

Além disso, verificou-se uma escola que, em parte não conquista os educandos para uma articulação de conhecimentos aparentemente distintos de forma criativa, mas que ainda não se inteirou de que existe uma cultura imediata que constitui a matriz de referência fundamental entre os educandos abordados no estudo e que não poderia ser em modo algum entendido como algo inexistente, invisível ou, quem sabe, até mesmo desnecessária.

Assim, pode-se inferir que, não há por parte da escola envolvida na pesquisa ações pedagógicas incisivas que enfatizem a cultura, tampouco associada ao conhecimento matemático, pois dentre os participantes da pesquisa, quando se perguntou sobre quais as atividades envolvendo cultura que são realizadas na escola, apenas (41\%) dos respondentes mencionaram alguma ação ou atividade estimulada pela escola.

Desse modo, as questões tratadas com a pesquisa possibilitaram subsídios e proposições para discussões ampliadas em sala de aula, querendo com isso, tornar o ambiente mais agradável para aprendizagem, apesar de algumas constatações que desfavorecem esta prática, mas que nos estimulam a realizar diferente e com mais ênfase no que diz respeito educação matemática.

O trabalho efetivado nos permitiu aguçar curiosidades, buscar conhecimentos e procurar fontes diversas de apoio, ouvir diferentes opiniões e formular novos questionamentos, permitiu-nos uma infindável gama de saberes que colocou-nos em contato com diferentes percepções dos educandos pesquisados, despertando-nos o interesse por mais pesquisas sobre a temática objetivando participações mais ativas na vida da escola nos favorecendo na obtenção de caminhos para outros estudos.

Dessa forma, os conteúdos culturais poderão ser problematizados e discutidos, comentados e analisados sob a percepção de alguns assuntos e temas matemáticos conhecidos, tais como: regra de três, logaritmos, simetrias, padrões geométricos, entre 
outros, que fizeram e fazem emergir conhecimentos matemáticos potencialmente dinâmicos para serem tomados como pontos de partida para a mediação Matemática, descortinando significados conceituais e metacognitivos relacionados à interação dos domínios da cultura - popular, da erudita ou de massa com a Matemática e com a escola como conseqüência e objetivo principal.

\section{CONSIDERAÇÕES FINAIS}

$\mathrm{O}$ intuito deste trabalho foi discorrer sobre a Cultura enquanto tema transversal e as articulações pedagógicas possíveis com a componente curricular Matemática no contexto escolar.

$\mathrm{Na}$ percepção de conceitos, valores, identidades, sociabilidades, trocas entre os participantes da pesquisa com diferentes formas de perceber o mundo, este trabalho constituiu-se em um movimento por esses campos com a intenção de se perceber as possibilidades de um espaço de trabalho, discussão e análise a respeito das questões enfocadas a respeito da cultura e do conhecimento matemático articulados.

Tentou-se enxergar como trabalhar no contexto escolar de forma mais ampla, distinta e prazerosa, com novas compreensões, isto é, com a tessitura de novos fios para uma rede que poderá começar a ser elaborada e que, acredita-se, poderá estar permanentemente incompleta e diversificada, contudo, em constante ampliação.

Partindo-se destas compreensões e apoiando-se na pesquisa realizada concluiu-se que a cultura poderia ser incluída no currículo através de metodologia que valorize a adoção de projetos, sobretudo, diante do caráter e da natureza interdisciplinar que possui.

Constatou-se que não há uma efetiva valorização da cultura na série pesquisada na unidade escolar, muito menos quando associada à educação matemática e que essa dissociação com a realidade cultural imediata com o trabalho pedagógico realizado na escola não estimula o conhecimento matemático por esse viés.

Verificou-se também que, as ações desenvolvidas na unidade escolar abordada no que tange ao conhecimento matemático, ocorrem dentro de expectativas corriqueiras com poucas ações diferenciadas, dinâmicas ou estimulantes.

Propõe-se a organização dos planos de estudo de forma interdisciplinar, dialogados e articulados, sugerindo-se que o processo pedagógico tenha como base o 
trabalho sistematizado com a participação dos docentes que atuam na unidade escolar enfocada, com audição sistemática dos educandos, com leituras de publicações específicas e com o uso de diversos recursos pedagógicos disponíveis na escola, com auto-avaliação permanente das ações efetivadas.

Ao mesmo tempo em que estas percepções práticas poderiam ser incorporadas ao fazer da escola, a escola poderia ser recriada. A comunidade escolar poderia se redescobrir, a valorizar e buscar os diferentes saberes culturais, para possivelmente, articular com o conhecimento matemático, ainda que como ponto de partida para outras inúmeras conjecturas e aprendizagens matemáticas.

Percebeu-se que, pode-se buscar, na Educação Matemática em articulação com a cultura, não a transferência apenas de dados e informações de um lugar a outro, mas oportunizar o surgimento de singularidades perceptivas que possam fazer frente ao engessamento exacerbado de algumas práticas pedagógicas.

O pretendido é que expressões, conotações e conceitos como: investimentos, isenções fiscais, patrocínios, incentivos fiscais, fundos financeiros, parcelas, arrecadações, ICMS e fomentos possam se constituir em definições e termos financeiros - econômico, que possam fazer parte do repertório dos estudantes e docentes.

Conjecturas e diálogos pedagógicos em se tratando da Educação Matemática que pontuem e ressaltem conceitos ligados às finanças e economia em geral, poderiam estar compondo o vocabulário dos docentes e estudantes para criação e resolução de problemas com questões matemáticas elaboradas e discutidas com os docentes mediadores, na unidade escolar pesquisada, para fortalecer o trabalho pedagógico com a temática.

Enfim, aprendeu-se muito e muito há para aprender, pois nos tornamos mais atentos para os muitos caminhos e as muitas possibilidades a serem pesquisadas, exploradas e estudadas, no que diz respeito ao conhecimento matemático.

É possível estudar a cultura em articulação com o conhecimento matemático, mediante as diferentes faces, falas, sentidos, imagens, produções e experiências que o cotidiano social e da escola proporciona como um farto material de pesquisa.

\section{REFERÊNCIAS}

ARANHA, Maria Lucia de Arruda. Filosofia da Educação. São Paulo: Moderna, 2014. 
AYALA, Marcos; AYALA; Maria Ignes Novais. Cultura Popular no Brasil. São Paulo: Ática, 2015.

BAHIA. Secretaria de Estado da Educação. Educação Básica da Rede Pública. Diretriz Curricular de Matemática - SEED, 2008.

BICUDO, Maria Aparecida Viggani. (Org.), Educação Matemática/ São Paulo: Centauro, 2005.

BRASIL. Ministério da Educação. Secretaria da Educação Fundamental. Parâmetros Curriculares Nacionais: Matemática. Brasília: MEC; SEM, 1997.

BRANDÃO, Carlos Rodrigues. A educação como cultura. São Paulo: Brasiliense, 2012.

CIFUENTES, José C. Uma via estética de acesso ao conhecimento matemático.

Boletim GEPEM, Rio de Janeiro, n.46, p.55-72, 2005.

COELHO, Teixeira. O que é indústria cultural. São Paulo: Brasiliense, 2014.

D'AMBROSIO, U. Da realidade à ação: reflexão sobre educação e matemática. São Paulo: Summus Editorial, 1986.

FREIRE, Paulo. Pedagogia da Autonomia: saberes necessários à prática educativa/São Paulo: Paz e Terra, 1996.

HELBEL. Ana Paula Tomazini. Matemática e Arte: possibilidades para o processo de ensino e aprendizagem da Geometria. Os desafios da escola pública paranaense na perspectiva do professor - Produções didático-pedagógicas - Cadernos PDE, 2013.

MACHADO, Cristina Gomes. Multiculturalismo: muito além da riqueza e da diferença. Rio de Janeiro: DP\&A, 2002.

MENDES, Iran Abreu. Práticas Socioculturais e Educação Matemática - Col. Contextos da Ciência. São Paulo: LF Editorial, 2017.

OLIVEIRA, Ana Paula Ferreira de. Matemática, linguagem e comunicação. MonteiroPB, 2014.

OLIVEIRA, A. J. N.; CARVALHO, M. C. F.; FIGUEIREDO, R. M. E. Contagem e aquisição de relações entre número e quantidade em crianças com idade escolar. In: FIGUEIREDO, R. M. E. et al. (Org.). Ensino de leitura, escrita e conceitos matemáticos. Belém: FIDESA/UNAMA, 2001. p. 26.

PARÂMETROS CURRICULARES NACIONAIS: Matemática/Secretaria de Educação Fundamental. - Brasília: MEC/SEF, 1998.

PARÂMETROS CURRICULARES NACIONAIS. Documento Introdutório. Ministério da Educação e do Desporto/Secretaria do Ensino Fundamental- SEF. Versão, 1996.

REVISTA TERRA MÃE. Secretaria de Comunicação Social. Publicação do Governo do Estado da Bahia. Ano 4, número 04, Salvador - BA, Produção gráfica Objectiva, 2018.

SAVIANI, Dermeval. Educação: Do senso comum a Consciência Filosófica. 13. ed. Campinas, São Paulo: Editora Autores Associados, 2013.

SILVA, M. M. Dificuldades de alunos do Ensino Médio em questões de Matemática 
do Ensino Fundamental. Dissertação de Mestrado em Educação em Ciências e Matemática. Faculdade de Física da PUCS-RS. Porto Alegre, 2006.

http://tedepucs.br/tdearquivos/24TDE-2007-05-22t073620z-618/público/347527pdf.

Último acesso: 02/12/2020.

SOARES, J. F., FARIAS, A. A., CESAR, C.C. - Introdução à Estatística. Rio de Janeiro, Ed. Guanabara Koogan S.A., 1991, p. 235.

Submetido em 12 de abril de 2020. Aprovado em 28 de novembro de 2020. 